\title{
Intrinsic transient tracheal occlusion training and myogenic remodeling of rodent parasternal intercostal fibers
}

\author{
Barbara K. Smith, PhD, PT; ${ }^{*}$ Sunita Mathur, PhD, PT; ${ }^{1}$ Fan Ye, MD, PhD; ${ }^{1}$ A. Daniel Martin, PhD, PT; ${ }^{1}$ Sara \\ Attia Truelson, BS $;^{2}$ Krista Vandenborne, PhD, PT; ${ }^{1}$ Paul W. Davenport, PhD $^{\mathbf{3}}$ \\ ${ }^{1}$ Department of Physical Therapy, College of Public Health and Health Professions, University of Florida, Gainesville, \\ FL; ${ }^{2}$ Department of Biology, College of Liberal Arts and Sciences, University of Florida, Gainesville, FL; \\ ${ }^{3}$ Department of Physiological Sciences, College of Veterinary Medicine, University of Florida, Gainesville, FL
}

\begin{abstract}
It is recognized that diaphragm muscle plasticity occurs with mechanical overloads, yet less is known about synergistic parasternal intercostal muscle fiber remodeling. We conducted overload training with intrinsic transient tracheal occlusion (ITTO) exercises in conscious animals. We hypothesized that ITTO would yield significant fiber hypertrophy and myogenic activation that would parallel diaphragm fiber remodeling. Sprague-Dawley rats underwent placement of a tracheal cuff and were randomly assigned to receive daily 10 min sessions of conscious ITTO or observation (sham) over 2 wk. After training, fiber morphology, myosin heavy chain (MHC) isoform composition, cross-sectional area, proportion of Pax7-positive nuclei, and presence of embryonic MHC (eMHC) were quantified. Type IIx/b fibers were $20 \%$ larger after ITTO training than with sham training (ITTO: $4,431+/-$ $676 \mu \mathrm{m}^{2}$, sham: $\left.3,689+/-400 \mu \mathrm{m}^{2}, p<0.05\right)$, and type I fibers were more prevalent after ITTO $(p<0.01)$. Expression of Pax 7 was increased in ITTO parasternals and diaphragm $(p<0.05)$. In contrast, the proportion of eMHC-positive fibers was increased only in ITTO parasternals $(1.2 \%$ [3.4\%-0.6\%], sham: $0 \%[0.6 \%-0 \%], p<0.05)$. Although diaphragm and parasternal type II fibers hypertrophy to a similar degree, myogenic remodeling appears to differ between the two muscles.
\end{abstract}

Key words: diaphragm, exercise training, fiber hypertrophy, muscle plasticity, muscle regeneration, myogenic activation, remodeling, respiratory muscles, tracheal occlusion, ventilation.

\section{INTRODUCTION}

The diaphragm contracts the earliest among the muscles of inspiration [1], and its displacement accounts for approximately 70 percent of the change in resting tidal volume [2]. Agonist intercostals in the parasternal region and lower external intercostals also have a large inspiratory mechanical advantage [3-4], and they contract in a predictable manner at rest [1,5]. Consequently, clinical weakness of either the diaphragm or intercostals results in paradoxical movements between the thorax and the abdomen [6] and impedes compensatory increases in ventilation during periods of elevated drive [7]. Rehabilitation with inspiratory muscle strength training (IMST) may counteract respiratory muscle insufficiency by improving maximal inspiratory pressure [8-9] and

\footnotetext{
Abbreviations: $\mathrm{A}_{\mathrm{A}}=$ area fraction, $\mathrm{ANOVA}=$ analysis of variance, $\mathrm{BW}=$ body weight, $\mathrm{COPD}=$ chronic obstructive pulmonary disease, $\mathrm{CSA}=$ cross-sectional area, $\mathrm{EMG}=$ electromyography, $\mathrm{eMHC}=$ embryonic myosin heavy chain, $\mathrm{IMST}=$ inspiratory muscle strength training, ITTO $=$ intrinsic transient tracheal occlusion, $\mathrm{MHC}=$ myosin heavy chain, $\mathrm{NIH}=$ National Institutes of Health, SHAM = sham-trained.

*Address all correspondence to Barbara K. Smith, PhD, PT; PO Box 100154, Gainesville, FL 32610-0154; 352-2736085; fax: 352-273-6109. Email: bksmith@phhp.ufl.edu http://dx.doi.org/10.1682/JRRD.2012.12.0232
} 
enhancing flow and volume compensations to loaded breathing [10]. However, the cellular remodeling responses of the inspiratory muscles to respiratory overloads are less understood, and their timing and magnitude could differ from those of the limb muscles.

It has been noted that the inspiratory intercostals appear to remodel with chronic changes in motor demands. Of the intercostal segments, the midthoracic external intercostals are best understood, and they have been found to atrophy [11] and hypertrophy [12] in clinical diseases and conditions that often occur in conjunction with chronic changes in inspiratory motor activity. Single airway occlusions in anesthetized animals also induce respiratory load compensation responses of the diaphragm and parasternal intercostals that include a prolonged inspiratory time and increased peak electromyography (EMG) [13]. Our laboratory found that acute bouts of intrinsic transient tracheal occlusion (ITTO) in anesthetized animals appeared to induce progressive load compensation responses throughout the respiratory pump, as measured by elevated diaphragm EMG activity, increased inspiratory time, and increased esophageal pressure [14]. When repeated for several days in conscious animals, ITTO load compensation responses also promote neural plasticity [15] and diaphragmatic fast fiber hypertrophy [16]. It is not known whether the plasticity to ITTO observed in diaphragmatic muscle fibers can be similarly achieved in the parasternal intercostals.

The model of ITTO developed in our laboratory $[14,17]$ provides a reversible, inescapable load to the respiratory muscles that is high intensity with short trial durations and resembles the initial occlusion-load phase of clinical IMST [9]. ITTO is advantageous, because it eliminates the need for permanent tracheostomies or tracheal banding techniques [15]. We recently reported the ITTO training model and its resultant hypertrophy in diaphragmatic type IIx/b fibers [16]. Mechanical strain promotes muscle fiber hypertrophy by facilitating protein synthesis pathways [18], and it also can activate satellite cells, muscle progenitors anatomically and functionally distinct from other myonuclei [19-20]. Pax7 is a transcription factor expressed by quiescent, activated, and proliferating satellite cells [21]. Satellite cell proliferation and differentiation facilitates myofiber growth and repair and supplies new myonuclei to the tissue. Developmental myosin heavy chain (MHC) isoforms, which are typically absent in mature skeletal muscle, reappear transiently in regenerating myotubes [22]. Since intramuscular tension is particularly high within intercostal muscle segments [23], we reasoned that these markers of myogenic activity could be present following ITTO.

In the current study, we investigated myogenic activity and morphological remodeling of parasternal muscle fibers in conscious rats after ITTO. The purpose of the study was twofold: to examine whether ITTO facilitated muscle fiber hypertrophy and myogenic activation in the parasternal muscles, and then to contrast the myogenic responses of the parasternals to the diaphragm. We hypothesized that respiratory loads generated during ITTO would result in significant hypertrophy and myogenic activity in the parasternal intercostals when compared with a surgical control group. Additionally, we hypothesized that the type and degree of myogenic activation of the parasternal intercostals of ITTO animals would be similar to diaphragm regenerative activity.

\section{METHODS}

Two experiments were conducted. First, we investigated whether daily sessions of ITTO loading would facilitate fiber hypertrophy and regeneration in the parasternal intercostals. Next, we compared the presence of myogenic biomarkers in the parasternal intercostals to the diaphragm after either ITTO or sham training. These experiments were an extension of our initial work on the ITTO model of inspiratory training and its use to study diaphragmatic hypertrophy [16].

\section{Animals}

Nineteen young-adult male Sprague-Dawley rats (Harlan Laboratories; Indianapolis, Indiana) were studied (Table). Animals were maintained in standard housing in the University of Florida animal care facility, in accordance with National Institute of Health's (NIH's) "Guide for the Care and Use of Laboratory Animals." A 12:12 h reverse light:dark cycle and ad libitum diet of animal chow and water were supplied. All animals underwent placement of a tracheal cuff and were randomly assigned to training groups.

\section{Occluder Placement}

For placement of the tracheal occluder cuff, spontaneously breathing animals were anesthetized with isoflurane gas $\left(2 \%-5 \%\right.$ in $\left.\mathrm{O}_{2}\right)$ and breathed room air. After an absence of corneal and paw-pinch reflexes was confirmed, 
Table.

Weight and age in sham-trained (SHAM) animals and animals treated with 10 sessions of intrinsic transient tracheal occlusion (ITTO). Two animals did not complete experimental protocol because of infection ( $n=1$, SHAM) and occluder failure $(n=1$, ITTO). There were no significant group differences.

\begin{tabular}{lcc}
\hline \multicolumn{1}{c}{ Measure } & $\begin{array}{c}\text { ITTO } \\
(\boldsymbol{n}=\mathbf{1 0})\end{array}$ & $\begin{array}{c}\text { SHAM } \\
(\boldsymbol{n}=\mathbf{9})\end{array}$ \\
\hline Age (d), Median (IQR) & & \\
$\quad$ Study Onset & $69(60-101)$ & $67(60-80)$ \\
Body Mass (g), Mean \pm SD & & \\
$\quad$ Study Onset & $284 \pm 56$ & $283 \pm 46$ \\
$\quad$ Study Conclusion & $318 \pm 31$ & $316 \pm 31$ \\
\hline IQR = interquartile range, SD = standard deviation. & \\
\hline \hline
\end{tabular}

the trachea was exposed using a ventral incision. A vascular occluder cuff (Fine Science Tools; Foster City, California) was sutured around the trachea, and the actuating line was externalized between the scapulae. To inflate the cuff bladder, the actuating line was connected to a saline-filled syringe. The inflated cuff closed the trachea and elicited ITTO. Deflation of the cuff fully restored the patency of the airway and removed the breathing load. The actuator line was stitched in place and the tracheal incision sutured.

During surgery and recovery, the body temperature was maintained at $37^{\circ} \mathrm{C}$ using a thermal pad. Animals received doses of buprenorphine $(0.01-0.05 \mathrm{mg} / \mathrm{kg}$ body weight $[\mathrm{BW}])$ and carprofen $(5 \mathrm{mg} / \mathrm{kg} \mathrm{BW})$ for analgesia and were rehydrated $(0.9 \%$ saline, $0.01-0.02 \mathrm{~mL} / \mathrm{g} \mathrm{BW})$ before anesthesia withdrawal. Animals were closely monitored for respiratory distress, infection, or pain. During the first four postoperative days, routine analgesics and anti-inflammatory medications were administered (buprenorphine $0.01-0.05 \mathrm{mg} / \mathrm{kg} \mathrm{BW}$ every $12-24 \mathrm{~h}$ and carprofen $5 \mathrm{mg} / \mathrm{kg} \mathrm{BW}$ every $24 \mathrm{~h}$ ).

\section{Training Protocol}

After a recovery period of 5-7 d, animals were assigned to an 11-session training intervention similar to our previous reports [15-16,24]. Experimental sessions occurred $5 \mathrm{~d} / \mathrm{wk}$ in the morning and lasted approximately $20 \mathrm{~min}$. On the first session, each animal was acclimatized to the study observation chamber for approximately $20 \mathrm{~min}$. During observation, no occlusions were administered.

\section{Sham Training}

In the subsequent daily experimental sessions (sessions 2-11), animals in the sham-trained (SHAM) group $(n=9)$ were placed in the observation chamber for $15 \mathrm{~min}$ of observation. The tracheal cuff was never inflated during observation sessions of the SHAM animals.

\section{Intrinsic Transient Tracheal Occlusion Training}

Animals in the ITTO group $(n=10)$ completed daily training sessions of $2.5 \mathrm{~min}$ of unobstructed breathing, 10 min of ITTO, and then 2.5 min of unobstructed breathing. A cuff pressure of $400-600 \mathrm{mmHg}$ was utilized to completely and reversibly occlude the trachea of rats. During ITTO, the tracheal cuff was inflated for approximately 5-8 s to elicit approximately eight respiratory attempts and then deflated for approximately 20-25 s. The onset and removal of ITTO was confirmed with analog tracings of the cuff pressure and plethysmograph recordings.

\section{Tissue Analysis}

One day after the last session, animals were anesthetized with isoflurane gas $\left(2 \%-5 \%\right.$ in $\left.\mathrm{O}_{2}\right)$. Anesthesia was confirmed by absent paw pinch and corneal reflexes, and then animals were euthanized by decapitation. The right third parasternal intercostal muscle was placed in salinemoistened gauze and chilled for 3-5 min [25-26], mounted with pins at resting length [27], and then embedded in mounting medium (Tissue-Tek ${ }^{\circledR}$ Compound, Sakura Finetek; Torrance, California) and quickfrozen with liquid nitrogen-chilled isopentane. In a subset of animals, the right midcostal diaphragm $(n=14$ : ITTO $=7$, SHAM $=7$ ) was preserved for immunofluorescent analysis of regeneration markers. An additional subset of left parasternal tissue $(n=8$ : ITTO $=4$, SHAM $=4$ ) was flash-frozen in liquid nitrogen for Western blot analysis. Specimens were stored in a $-80^{\circ} \mathrm{C}$ freezer until analysis. For all immunofluorescence analyses, tissue was sectioned transversely at the midbelly $(10 \mu \mathrm{m})$ with a cryostat microtome (Microm HM505; Walldorf, Germany). Sections were air-dried at $25^{\circ} \mathrm{C}$ for $30 \mathrm{~min}$ before histological processing.

\section{Experiment 1: Effect of Intrinsic Transient Tracheal Occlusion Training Sessions on Parasternal Morphology, Hypertrophy, and Myogenic Immunofluorescence}

Cross-sectional area (CSA), fiber composition, and cellular morphology in the third parasternal muscles were compared from animals that received $10 \mathrm{~min}$ of ITTO daily and SHAM animals. 
Experiment 2: Effect of Intrinsic Transient Tracheal Occlusion on Myogenic Activation of Respiratory Muscles

The presence of Pax7-positive nuclei and embryonic MHC (eMHC) expression in the parasternals was compared with the diaphragm muscles after ITTO or SHAM conditioning.

\section{Myosin Heavy Chain Immunofluorescence}

Slides were first permeabilized with 0.5 percent Triton-X100 in phosphate-buffered saline. The samples were incubated with primary antibodies for laminin (1:200, Laboratory Vision; Fremont, California), type I MHC (A4.840, 1:15, Developmental Studies; Iowa City, Iowa), and type IIa MHC (SC-71, 1:50, Developmental Studies), followed by secondary antibody incubation with rhodamine, Alexa Fluor 350, and Alexa Fluor 488 (Invitrogen; Carlsbad, California). Coverslips were mounted with Vectashield medium (Vector Laboratories; Burlingame, California). Samples were visualized by fluorescence microscopy at $10 \times$ magnification (Leica DM LB; Solms, Germany) using Leica N21 (BP 515-560 nm), GFP (BP 470/40 nm), and A4 (BP 360/40 nm) filter cubes. The fluorescence exposure times, gain, and gamma settings were maintained across specimens. Single-layer images were captured with a digital camera, and the scope software (LAS software, Leica, version 3) produced an overlay image. An investigator blinded to the study quantified CSA using laminin-fluoresced images of fibers (Scion Image software, NIH; Bethesda, Maryland). The CSA results were then superimposed onto the overlay image provided by the microscope. To calculate the fiber type and the area fraction $\left(\mathrm{A}_{\mathrm{A}}\right)$ occupied by each fiber type, we counted at least 250 fibers from each muscle.

\section{Myogenic Immunofluorescence}

We identified satellite cells in muscle specimens by labeling Pax7 (1:50, Developmental Studies), a transcription factor specific for quiescent, activated, and proliferating satellite cells. Separately, we also labeled eMHC (1:50, Developmental Studies) expressed in differentiating myotubes. Slides were air-dried at $25^{\circ} \mathrm{C}$, fixated with $1: 1$ acetone-methanol solution, and then rinsed in phosphate-buffered saline. Next, slides were blocked with Pierce's Superblock (Pierce Biotechnology; Rockford, Illinois) for $60 \mathrm{~min}$ at $25^{\circ} \mathrm{C}$. Sections were incubated in primary antibodies for laminin (1:200, LabVision; Fremont, California) and either eMHC (1:50, F1.652) or
Pax7 (1:50) in 10 percent normal goat serum and phosphate-buffered saline overnight at $4^{\circ} \mathrm{C}$. Secondary antibody incubation occurred with rhodamine (1:500) and Alexa Fluor 488 (1:300) antibodies (Invitrogen) in 10 percent normal goat serum and phosphate-buffered saline for $2 \mathrm{~h}$ at $25^{\circ} \mathrm{C}$ in the dark. Specimens were mounted in Vectashield medium with DAPI (Vector Laboratories).

Pax7 and eMHC samples were visualized separately with fluorescence microscopy at $20 \times$ magnification, using Leica N21 (BP 515-560 nm), GFP (BP 470/40 nm), and A4 (BP 360/40 nm) filter cubes. The scope (Leica DM LB) then provided an overlay image that merged the blue, green, and red fluorescence (LAS software, Leica, version 3). The fluorescence exposure times, gain, and gamma settings were maintained across specimens. Images that contained background nonspecific fluorescence in any layer were thrown out and the processing was repeated. The overlay images were de-identified with a random number and the proportions of Pax 7 nuclei or eMHC-positive fibers were calculated from a minimum of 250 fibers per muscle specimen (Figure S1 and S2 in Supplemental Data, available online only). Pax7 identification was confirmed among three investigators blinded to group assignment. Two separate investigators blinded to group assignment confirmed positive eMHC fiber identification.

\section{Muscle Fiber Morphology}

Ten-micrometer transverse serial sections were acquired with a cryostat cooled to $-20^{\circ} \mathrm{C}$ (Microm HM505; Walldorf, Germany). Sections were stained with hematoxylin and eosin, and coverslips were mounted with Permount medium (Fisher Scientific). Specimens were visualized with bright field microscopy (Leica DM LB) at $40 \times$ magnification. Twenty randomly selected images were analyzed from each right third parasternal.

An analysis of the area of tissue submitted to damage-regeneration phenomena was undertaken using a systematic point-counting technique [28-29]. Point-counting was conducted by overlaying a 63-point grid over each of the 20 images (a total of 1,260 points per muscle, per animal), using Adobe Photoshop CS3 software (Adobe Corporation; San Jose, California). The tissue underneath each point on the grid was classified into one of nine morphological categories and then grouped as normal muscle, connective tissue, or remodeled tissue. Connective tissue was identified as endomysial or perimysial tissue or 
fibroblasts. Remodeled tissue included small or angular fibers, internally nucleated fibers, inflamed or necrotic fibers, abnormal cytoplasm, inflammatory cells, or adipocytes (Figure S3 in Supplemental Data, available online only). In a sample of three animals, two study investigators blinded to group assignment separately analyzed all images, and then each reviewer's classifications were compared. The level of agreement (intraclass correlation coefficient) of the fiber classifications was 0.95 . An $\mathrm{A}_{\mathrm{A}}$ was calculated for each category of tissue as follows:

$$
\mathrm{A}_{\mathrm{A}}=\left(\sum \text { counts in category }\right) /(\text { total counts }) \times 100 \% \text {. }
$$

\section{Western Blot}

The presence of eMHC was confirmed in the ITTO parasternal tissue using a subset of eight animals (ITTO = 4 , SHAM =4). For extraction of protein, frozen left intercostal muscle ( $\sim 30 \mathrm{mg})$ was triturated in a radioimmunoprecipitation assay buffer and protease inhibitor cocktail (1:1000, SigmaFast, Sigma-Aldrich; St. Louis, Missouri). Samples were vortexed and centrifuged, and the supernatant was carefully removed. The concentration of protein in the supernatant was calculated against known protein assay reagents (BioRad; Hercules, California).

Equal concentrations of the isolated protein were combined with lithium dodecyl sulfate buffer and reducing agent. One-dimensional sodium dodecyl sulfate polyacrylamide gel electrophoresis was conducted with the $\mathrm{Nu}$-Page mini-gel system and bis-tris 4-12 percent minigel (Invitrogen; Carlsbad, California). Gels were transferred to a nitrocellulose membrane, and Ponceau S stain identified molecular mass markers. Membranes were blocked with 5 percent milk in tris-buffered saline with Tween and incubated with eMHC (1.652, 1:500 dilution, Developmental Studies) primary antibody and milk buffer at $4^{\circ} \mathrm{C}$ overnight. The gel was rinsed and then incubated for $1 \mathrm{~h}$ in peroxidase-conjugated secondary antibody (Rockland Laboratories; Gilbertsville, Pennsylvania). After further rinses in tris-buffered saline, we applied enhanced chemiluminescence reagents (Bio-Rad) and exposed the protein bands with X-ray film. The intensity of the bands was compared to a dilution curve and quantified with Image $\mathbf{J}$ software $(\mathrm{NIH})$.

\section{Statistical Analysis}

Statistical analysis was conducted using SPSS Statistics 20 software (IBM Corporation; Armonk, New York).
Kolmogorov-Smirnov and Shapiro-Wilk tests were used to examine the assumptions of normality and homogeneity of variance. Animal characteristics were assessed using independent samples $t$-tests. For each animal, the mean CSA of each fiber type was calculated for each muscle. Parasternal intercostal muscle fiber typing and morphology were then analyzed with two-way analyses of variance (ANOVAs) (MHC $\times$ group) and then HolmSidak-corrected pairwise contrasts when needed. Myogenic activation was analyzed with Mann-Whitney U tests. Nonparametric data are presented as median \pm interquartile range, while parametric data are provided as mean \pm standard deviation. The level of significance was $p<0.05$.

\section{RESULTS}

Rats tolerated the ITTO sessions well, and $>95$ percent of sessions were successfully completed. Two animals did not complete the experimental protocol because of infection $(n=1$, SHAM) or occluder failure $(n=1$, ITTO), leaving 17 animals available for analysis. The Table depicts the age and body mass of each group of animals. The age and weight of animals was similar between groups. Animals gained weight during the experiment (repeated-measures ANOVA, main effect, $p<$ 0.01 ), and the weight gain did not differ between groups.

\section{Intrinsic Transient Tracheal Occlusion and Parasternal Intercostal Muscle Fiber Cross-Sectional Area}

The CSA of the parasternal intercostal muscles (Figure 1(a)) differed according to both the training group and the fiber type. The CSA of type IIx/b fibers was 20 percent larger in the ITTO group than the SHAM group (ITTO: 4,431 $\pm 676 \mu \mathrm{m}^{2}$, SHAM: 3,689 $\pm 400 \mu \mathrm{m}^{2}$, ANOVA interaction effect, $p<0.05$ ). Type I and IIa CSA did not differ by training group. In both groups, type IIx/ $b$ fibers were significantly larger than type IIa or type I fibers $(p<0.001)$.

\section{Fiber-Type Proportions of Third Parasternal Intercostal Muscles}

The third parasternal intercostal muscle contained a majority of fast type IIx/b afibers (Figure 2). The proportion (ITTO: $0.18 \pm 0.08$, SHAM: $0.12 \pm 0.05$ ) and fiber $\mathrm{A}_{\mathrm{A}}$ (MHC A $\mathrm{A}$, ITTO: $0.09 \pm 0.04$, SHAM: $0.05 \pm 0.02$ ) of type I fibers was greater in ITTO animals (ANOVA 


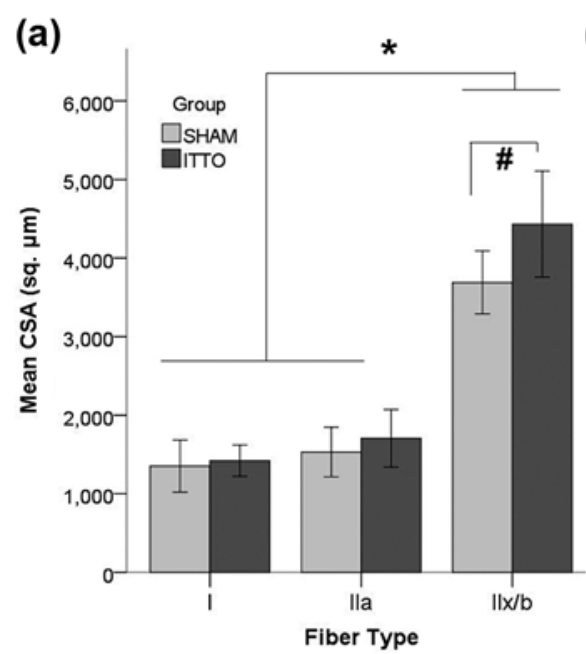

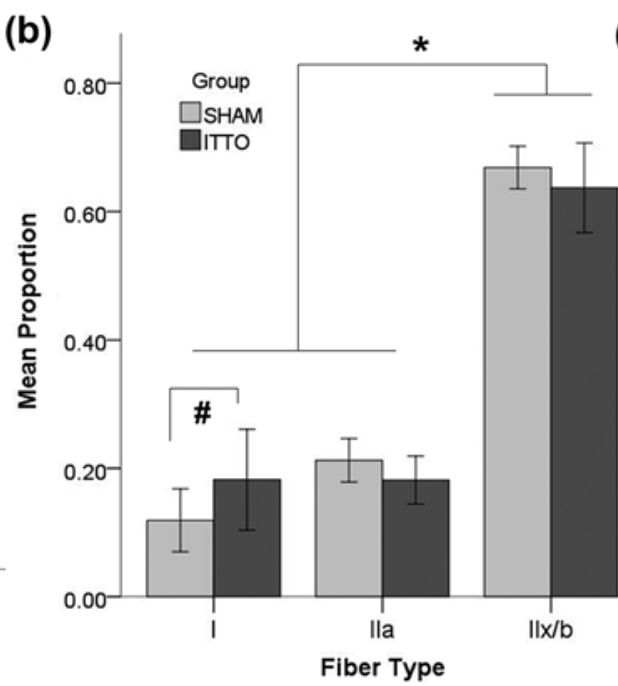

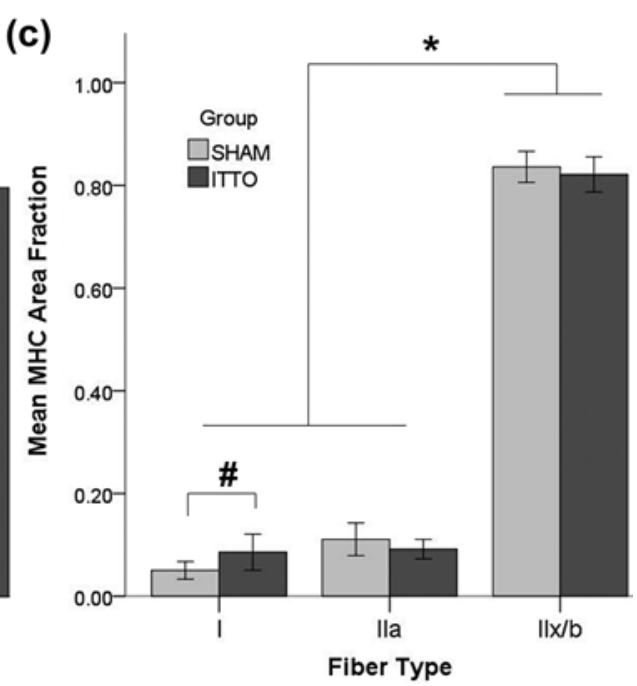

\section{Figure 1.}

Remodeling of third parasternal intercostals after 10 min intrinsic transient tracheal occlusion (ITTO) conditioning sessions. After 10 training sessions, (a) cross-sectional area (CSA) of type IIx/b fibers was greater in ITTO group than sham-trained (SHAM) group ( ${ }^{\#} p<$ 0.05). Regardless of group assignment, type IIx/b fibers were larger than type I or Ila fibers $\left({ }^{*} p<0.001\right)$. (b) ITTO animals contained larger proportion of type I fibers $\left({ }^{\#} p<0.05\right)$. Type IIx/b fibers were more prevalent than type I or type Ila $\left({ }^{*} p<0.001\right)$. (c) Type I myosin heavy chain $(\mathrm{MHC})$ area fraction $\left(\mathrm{A}_{\mathrm{A}}\right)$ was greater in ITTO group $(\# p<0.05)$. In addition, type IIx/b fibers occupied largest $A_{A}\left({ }^{*} p<\right.$ $0.001)$.
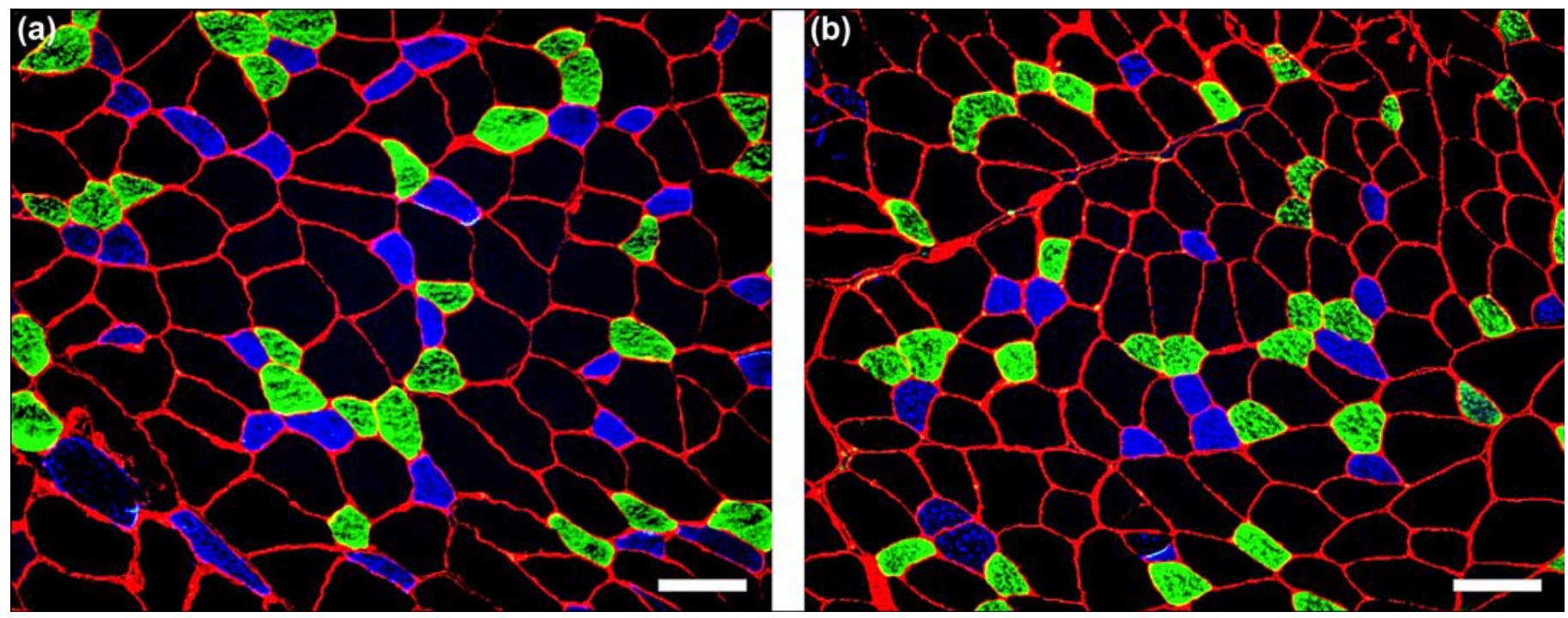

\section{Figure 2.}

Immunofluorescence analysis of myosin heavy chain isoform in third parasternal intercostal muscle. Parasternal intercostal muscles from (a) intrinsic transient tracheal occlusion-trained animal and (b) sham-trained animal. Type I fibers fluoresced blue, type Ila illuminated green, and type $\| \mathrm{x} / \mathrm{b}$ fibers remained free of fluorescence. Green and red layers were acquired with exposure times between 150 and $220 \mathrm{~ms}$, while blue layer required exposure times of 350-450 ms. Gain was 2.0. Images were captured with $10 \times$ eyepiece and 10x magnification. Average cross-sectional area of each fiber type in a muscle sample was calculated from at least 250 fibers. Scale bar $=100 \mu \mathrm{m}$. 
interactions, $p<0.05$ ) (Figure 1(b) and 1(c)). Regardless of the group, the intercostals contained more type IIx/b fibers and occupied a larger area than either type IIa or type I fibers (ANOVA main effects, $p<0.001$ ).

\section{Morphological Assessment of Third Parasternal Intercostal Muscles}

The morphological $\mathrm{A}_{\mathrm{A}}$ did not differ according to group. The majority of the parasternal intercostal muscle fibers were normal fibers that occupied a significantly larger $\mathrm{A}_{\mathrm{A}}$ than connective tissue or remodeling fibers $(p<$ 0.001). The $A_{A}$ of connective tissue exceeded the $A_{A}$ of remodeled muscle fibers $(p<0.001)$. Only minute quantities of remodeling tissue were identified. Internally nucleated cells occupied the largest $\mathrm{A}_{\mathrm{A}}$ (pooled $\mathrm{A}_{\mathrm{A}}: 1.5 \% \pm$ $1.0 \%$ ), suggesting a small yet active muscle regeneration process. Figure 3 depicts the remodeling features and $\mathrm{A}_{\mathrm{A}}$ of remodeling tissue in the parasternal intercostal muscles. Neither group contained areas of widespread cellular membrane disruption or inflammatory cell abundance indicative of an acute muscular injury.

\section{Intrinsic Transient Tracheal Occlusion and Pax7-Positive Nuclei in Respiratory Muscles}

Pax7-positive nuclei were identified by green fluorescent nuclei located between the basal lamina and the extracellular membrane and overlaid by DAPI-positive tissue. Figure 4 illustrates $\operatorname{Pax} 7$ microscopy from an ITTO and a SHAM animal. Of the sample used to compare myogenic activity, diaphragm tissue was unavailable from two animals (ITTO $=1$, SHAM $=1)$. There was a significant main effect for training on the number of fibers containing Pax7-positive nuclei (ANOVA, $F=6.205, p<$ 0.05 ). Animals exposed to ITTO training contained more Pax7-positive nuclei in the diaphragm and parasternal muscles than SHAM animals (diaphragm, ITTO: $7.0 \% \pm$ 4.2\%, SHAM: $4.6 \% \pm 2.9 \%$; parasternal, ITTO: $10.1 \% \pm$ 2.3\%, SHAM: $5.5 \% \pm 2.2 \%$; Figure 5(a)). (a)

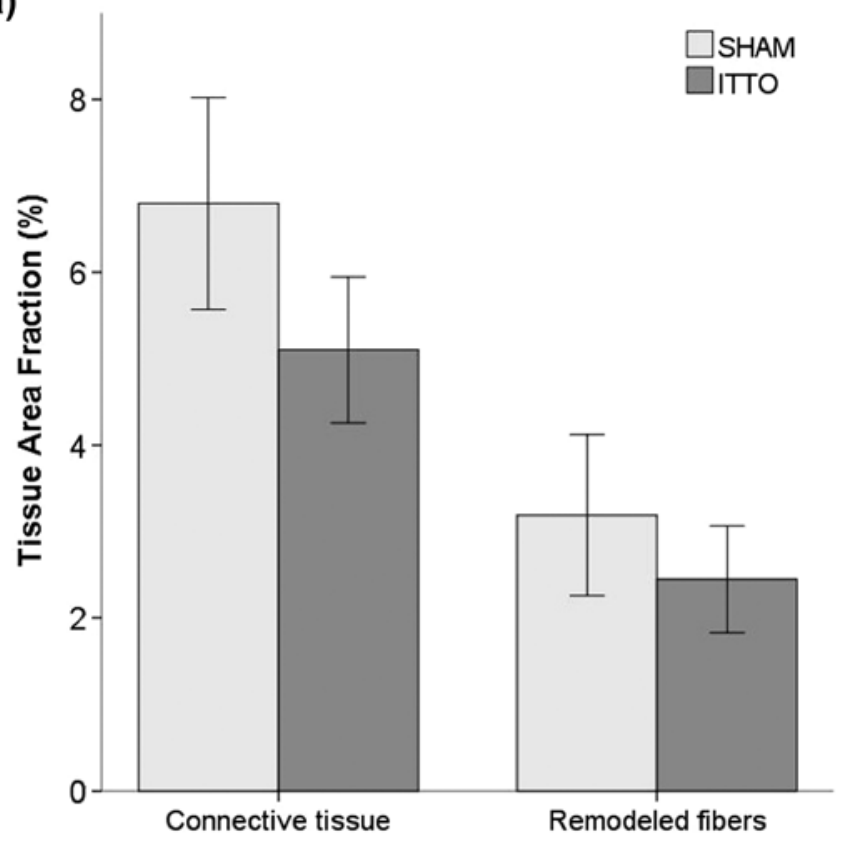

(b)

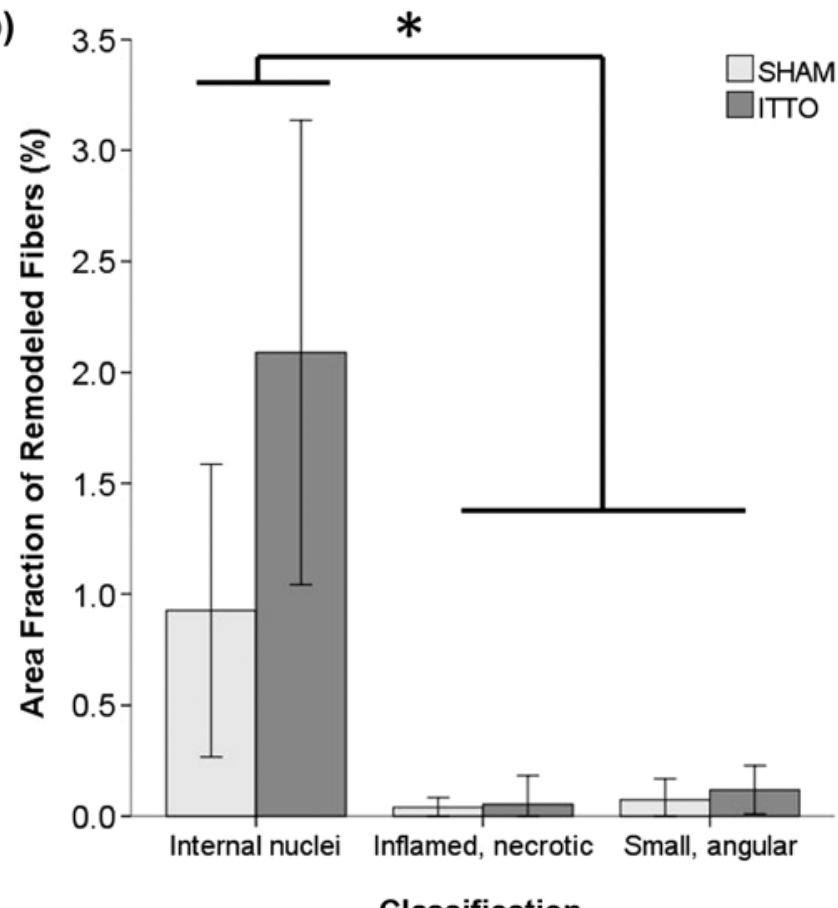

Figure 3.

Morphological assessment of third parasternal intercostal muscles in animals that received intrinsic transient tracheal occlusion (ITTO) training or sham training (SHAM). (a) Area fraction $\left(A_{A}\right)$ of remodeling fibers and connective tissue in ITTO and SHAM animals. $A_{A}$ was not different based on group assignment. (b) Classifications of remodeling fibers. In each category, no $A_{A}$ differences between training groups $\left({ }^{*} p<0.001 \mathrm{~A}_{A}\right.$ of internal nuclei, compared with inflamed necrotic and small angular $\mathrm{A}_{\mathrm{A}}$ categories). 

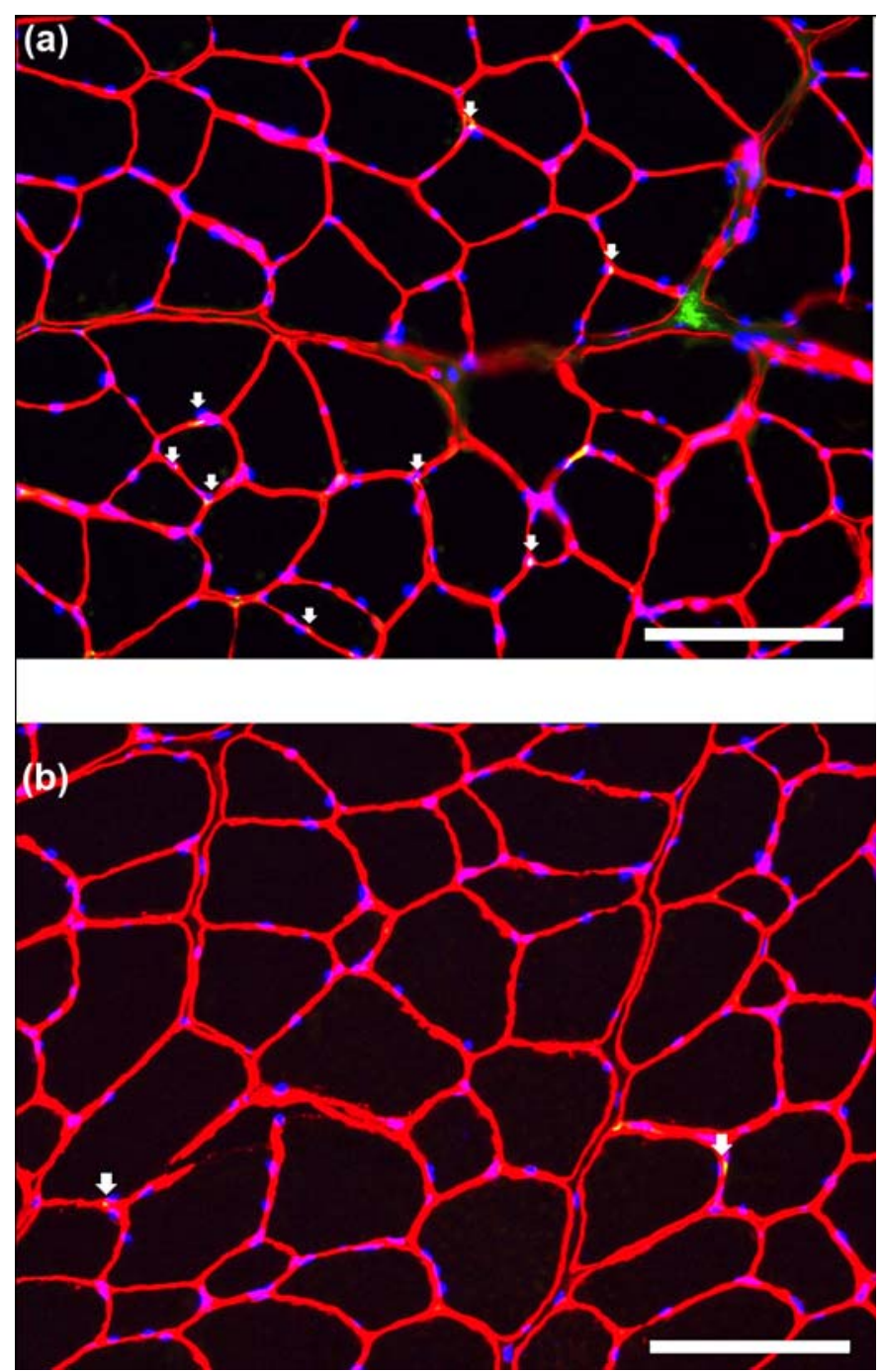

Figure 4.

Immunofluorescent images of Pax7 in third parasternal intercostals from (a) intrinsic transient tracheal occlusion-trained animal and (b) sham-trained animal. Arrows show Pax7-positive nuclei, defined as areas that fluoresced with Pax7-AlexaFluor-488, were contained within sarcolemma and basal membrane and colocalized with DAPI staining. Each image layer was acquired with exposure times of $150-220 \mathrm{~ms}$ and gain of 2.0. At least 250 fibers were analyzed with $10 \times$ eyepiece and $20 \times$ magnification. Scale bar $=100 \mu \mathrm{m}$.

\section{Intrinsic Transient Tracheal Occlusion and Embryonic Myosin Heavy Chain-Positive Fibers in Respiratory Muscles}

Intensely fluorescing areas within the exact borders of the sarcolemma were interpreted as eMHC-positive fibers. Fibers with a faint or incomplete area of fluores- cence were not counted. The eMHC-positive fiber CSA was small $\left(465 \pm 78 \mu \mathrm{m}^{2}\right)$. Data for eMHC were powertransformed in order to meet normality assumptions for two-way ANOVA. There was a significant interaction between the type of training and muscle $(F=3.764, p<$ $0.05)$. That is, eMHC-positive fibers were prevalent in ITTO parasternal tissue (ITTO: $1.2 \%$ [3.4\%-0.6\%], SHAM: $0 \%$ [0.6\%-0\%], Figure 5(b)), but not in the diaphragm. Western blot analysis revealed small yet distinct bands at $\sim 200 \mathrm{kDa}$. The signal intensity tended to be larger in the ITTO animals, but individual readings were variable and did not reach statistical significance (MannWhitney $\mathrm{U}, p=0.12$, Figure 5(c)).

\section{DISCUSSION}

The current study measured the CSA and myogenic remodeling responses of parasternal inspiratory intercostal muscles following brief, intense pressure overload training. There are two advantageous aspects of this investigation. First, we present novel analyses of the hypertrophic and myogenic responses to training in the parasternal intercostals and compare these findings to the diaphragm. Additionally, fiber remodeling was elicited from the innovative ITTO model of IMST, which provided an occlusive stimulus needed to recruit fast-fatigable fibers [30] while avoiding the inflammatory responses incurred by chronic tracheal banding or tracheostomy. The results support the hypothesis that ITTO training would be associated with fiber remodeling in the rodent parasternal intercostal muscles. However, we reject our hypothesis that remodeling of the parasternals would mirror those of the diaphragm. The distinct patterns of myogenic marker prevalence in these respiratory muscles may offer insights into their motor recruitment and remodeling capabilities with clinical IMST.

In patients with respiratory insufficiency, IMST has been found to increase strength [12], reduce dyspnea [31], and improve weaning from mechanical ventilation [9]. Functional gains in patients have been observed in conjunction with fiber hypertrophy and regeneration of the lower intercostals [12,32]. However, exerciseinduced cellular remodeling is not well understood in the human diaphragm or parasternal intercostals. The ITTO model could offer potential insights on the rate, extent, and location of neuromuscular plasticity induced by IMST and enable a more direct investigation of optimal 

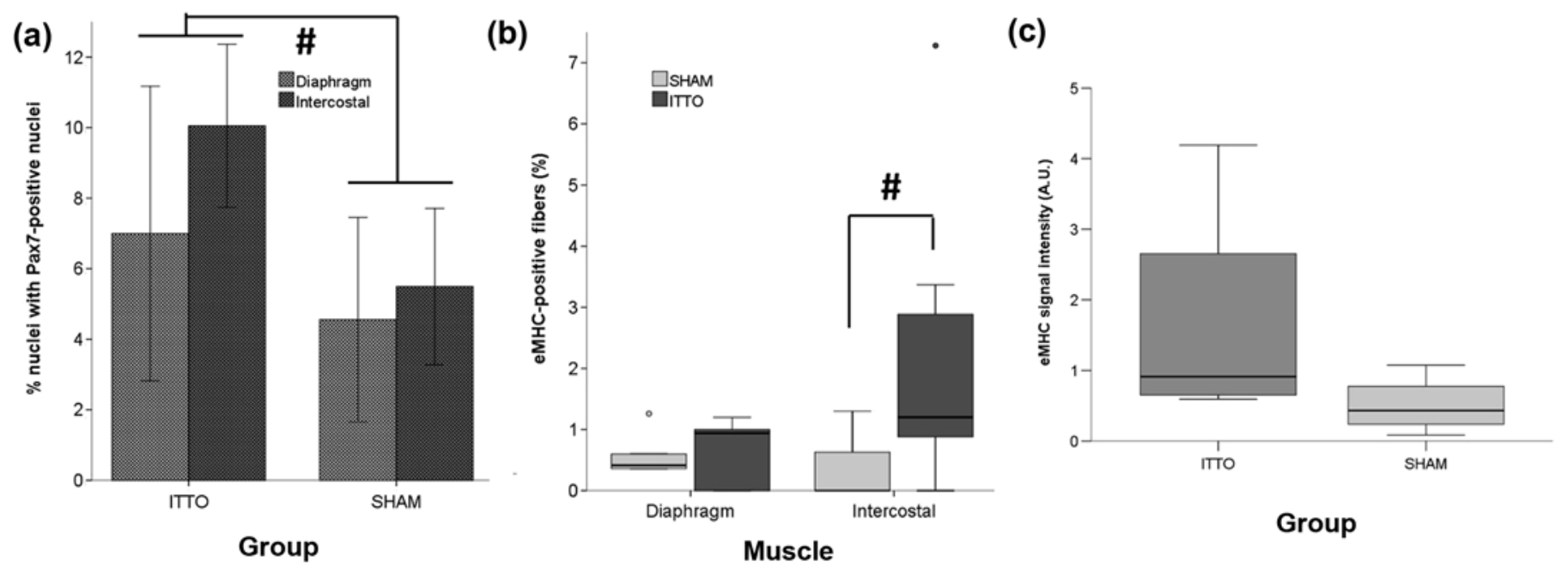

Figure 5.

Expression of myogenic biomarkers in respiratory muscles. (a) Proportion of Pax7-positive nuclei (mean \pm standard deviation) was greater in intrinsic transient tracheal occlusion (ITTO) diaphragm and parasternal intercostal tissue than with sham-trained (SHAM) animals $\left({ }^{\#} p<0.05\right)$. (b) Presence of embryonic myosin heavy chain (eMHC) (median, interquartile range [IQR]) was increased only in parasternal intercostal muscles of ITTO animals $\left({ }^{\#} p<0.05\right)$. (c) With Western blot, signal intensity of eMHC protein (median, IQR) in subset $(n=8)$ of parasternal intercostal muscles was variable in ITTO animals and did not differ significantly between groups $(p=$ 0.12). Protein measures were normalized to standard dilution curve.

exercise doses to yield changes in muscular endurance and power. Research on intercostal remodeling is scant but could be especially crucial for managing diseases where the diaphragm is at a mechanical disadvantage (i.e., chronic obstructive pulmonary disease [COPD]) [31] or paralyzed (i.e., cervical spinal cord injury, multiple sclerosis) [33-34].

After only 10 training sessions, type IIx/b fibers were significantly $(+20 \%)$ larger in the parasternals, which was consistent with our recent report of rapid, fast-fiber hypertrophy in the midcostal diaphragms of ITTO-trained animals [16]. Acute anabolic responses can be detected in humans and rodents within hours of the first strengthtraining bout [35-37]. Fast-fiber hypertrophy may occur after ITTO training [38-39], because airway occlusion appears necessary to appreciably recruit fast-fatigable rodent diaphragm fibers [30]. Type IIx/b fibers are prevalent in parasternal tissue, but the time and extent to which they became recruited during ITTO is not well understood. However, human patients reach peak volitional inspiratory pressure within 15-20 s of occlusion [40-41]. We did not measure pressure generated by the animals during ITTO but consistently observed costal retractions reflecting robust respiratory efforts with occlusions.
Fiber hypertrophy occurred together with a greater prevalence of Pax7-positive nuclei in both the ITTO diaphragm and parasternals, an indication of satellite cell activity [21]. Both in rodents and humans, resistance training increases satellite cell content, with concomitant gains in fiber CSA and muscle force [42-44]. The pattern of satellite cell accretion may retain an isoform specificity [45], and recent work found strength training of humans promoted fast-fiber hypertrophy, accompanied by a greater satellite cell content in type II, but not type I fibers [42]. Pax 7 is downregulated during terminal differentiation of myotubes, leaving the possibility that some cells were not counted [46]. Although it has been noted previously that the fiber-type distribution of satellite cells may differ between slow and fast limb muscles [47], this was not a primary aim of this study. The naturally occurring proportions of $\operatorname{Pax} 7, \operatorname{Pax} 3$, and other regenerative transcription factors also appear species- and muscledependent $[32,48]$ and require further investigation.

While similar hypertrophic responses were detected in both the diaphragm and parasternal intercostal muscles, only the parasternals contained an increased prevalence of slow fibers and eMHC fiber expression. These distinctions suggest ITTO could have elicited different patterns 
of loading and remodeling in the diaphragm and parasternals. Clinically, a chronically elevated work of breathing is associated with a fast-to-slow MHC shift in the parasternals but not the diaphragms of patients with COPD [49]. Similarly, early and regular muscular activity appears to elicit a greater expression of slow MHC in the fast muscles of rodents, but only when the muscle is exposed to damage-regeneration phenomena [50]. Recruitment of inspiratory synergistic muscles enhances maximal respiratory pressure and reduces diaphragmatic muscular tension [51], at the cost of high intramuscular tension within individual intercostal segments [23]. Consequently, progressive or sustained inspiratory loading may render the intercostals susceptible to fatigue or injury [52-53]. In contrast, diaphragmatic activation becomes attenuated by sustained loaded breathing [54], which could minimize the risk of diaphragmatic fatigue, even in the presence of task failure. While the recruitment patterns of the lower intercostals are best understood, it is reasonable to speculate that ITTO training could recruit the parasternal segments and subsequently promote myogenic remodeling [55]. While it has been previously reported that ITTO facilitated diaphragm EMG [14], interpretation of the current findings in the context of parasternal muscle loading must be made cautiously without parasternal EMG data during ITTO.

Although ITTO appeared to promote modest Pax7 and eMHC expression, we did not observe widespread regenerative activity akin to large induced mechanical or chemical injuries [56-58]. In conjunction, hematoxylin and eosin staining did not reveal large quantities of small or centrally nucleated fibers. Using different methodologies, McCarthy et al. [59] and Wang and McPherron [60] tested the necessity of satellite cells for fiber hypertrophy. Both studies noted that satellite cell activation was not required to elicit short-term fiber hypertrophy, yet McCarthy et al. observed that hyperplasia and fiber regeneration appear to be satellite cell dependent [59]. The separate and synergistic roles of fiber hypertrophy and fiber regeneration remain topics of great interest and offer potential avenues for promoting muscle rehabilitation without inducing injury [61]. We note that the number of Pax7-positive fibers observed in this study is relatively small when compared with the numbers reported in typical slow-twitch muscles. Interestingly, the proportions of eMHC-positive fibers in the ITTO parasternals were similar to levels reported in humans following strength training [62].
We acknowledge that there are limitations to the study design. Analysis of single muscle fibers permits more precise measurements at the optimal length for force generation [63]. We elected to analyze fiber bundles at resting length in order to capture greater quantities of muscle fibers using standardized cryopreservation techniques [25-27]. In a subset of randomly selected animals ( $n=3$ from each group), electron microscopy confirmed that the resting diaphragm and parasternal sarcomere lengths were equivalent between the groups $(p=0.96)$. Further, the study did not prospectively address whether ITTO training modified minute ventilation, EMG, or muscle force mechanics. Additionally, single occlusions in anesthetized animals robustly facilitate the lower external intercostals to a greater extent than the diaphragm or parasternals [13] and thus may undergo an even greater relative muscular remodeling with ITTO. Additional study is needed regarding in vivo activation of the diaphragm and parasternals using EMG during ITTO in order to further elucidate mechanisms of remodeling. We recognize that all these considerations could have important implications regarding the exercise doses recommended for patient use, and they require further study.

\section{CONCLUSIONS}

Ten sessions of ITTO were associated with increased CSA of type IIx/b muscle fibers and increased prevalence of Pax7-positive nuclei identified in the diaphragm and parasternal intercostal muscles. Further, the additional fast to slow fiber shift and eMHC-positive fibers suggested differences in the loading and remodeling of the parasternal intercostals. It is recommended that future studies address the functional transcriptional and translational pathways that accompany respiratory muscle training and examine the force adaptations of the respiratory muscles to provide us with an understanding of the mechanisms underlying muscle adaptation for clinical rehabilitation.

\section{ACKNOWLEDGMENTS}

\section{Author Contributions:}

Study concept and design: P. W. Davenport, S. Mathur, A. D. Martin, B. K. Smith, K. Vandenborne.

Acquisition of data: B. K. Smith, S. Mathur, F. Ye, S. Attia Truelson, P. W. Davenport. 
Analysis and interpretation of data: B. K. Smith, S. Mathur, F. Ye, S. Attia Truelson, P. W. Davenport.

Drafting of manuscript: P. W. Davenport, A. D. Martin, B. K. Smith, S. Mathur, F. Ye, S. Attia Truelson, K. Vandenborne.

Critical revision of manuscript for important intellectual content: P. W. Davenport, A. D. Martin, B. K. Smith, S. Mathur, F. Ye, S. Attia Truelson, K. Vandenborne.

Financial Disclosures: The authors have declared that no competing interests exist.

Funding/Support: Training support to B. K. Smith was provided by the NIH (grants T32 HD043730 and K12HD055929-02). Some disposable supplies were provided by the NIH (grant HD059751-01A1 to K. Vandenborne) and by a Howard Hughes Medical Institutesponsored minigrant to S. Attia Truelson. The A4.840, SC-71, Pax, and F1.652 antibodies generated by Helen M. Blau were obtained from the Developmental Studies Hybridoma Bank developed under the auspices of the National Institute of Child Health and Human Development and maintained by the Department of Biology, University of Iowa, Iowa City, Iowa.

Additional Contributions: We express gratitude to Mark Hotchkiss, Katherine Pate, and Vipa Bernhardt for their assistance with animal care and tissue collection. We thank the University of Florida Electron Microscopy Core Laboratory for assistance with ultrastructural assessments. S. Mathur is now with the Department of Physical Therapy, University of Toronto, Toronto, Ontario, Canada; F. Ye is with the Department of Applied Physiology and Kinesiology, University of Florida, Gainesville, Florida; and S. Attia Truelson completed her MD (Doctor of Medicine) degree and is with the Department of Internal Medicine, University of Florida, Miami, Florida.

Institutional Review: The experimental procedures were approved and overseen by the University of Florida Institutional Animal Care and Use Committee.

\section{REFERENCES}

1. Saboisky JP, Gorman RB, De Troyer A, Gandevia SC, Butler JE. Differential activation among five human inspiratory motoneuron pools during tidal breathing. J Appl Physiol. 2007;102(2):772-80. [PMID:17053105] http://dx.doi.org/10.1152/japplphysiol.00683.2006

2. Farkas GA, Cerny FJ, Rochester DF. Contractility of the ventilatory pump muscles. Med Sci Sports Exerc. 1996; 28(9):1106-14. [PMID:8882997] http://dx.doi.org/10.1097/00005768-199609000-00005

3. Butler JE, Gandevia SC. The output from human inspiratory motoneurone pools. J Physiol. 2008;586(5):1257-64. [PMID:17974589] http://dx.doi.org/10.1113/jphysiol.2007.145789

4. De Troyer A, Kirkwood PA, Wilson TA. Respiratory action of the intercostal muscles. Physiol Rev. 2005;85(2):717-56. [PMID:15788709] http://dx.doi.org/10.1152/physrev.00007.2004

5. De Troyer A. The electro-mechanical response of canine inspiratory intercostal muscles to increased resistance: The cranial rib-cage. J Physiol. 1992;451:445-61. [PMID:1403817]

6. De Troyer A, Estenne M. Coordination between rib cage muscles and diaphragm during quiet breathing in humans. J Appl Physiol. 1984;57(3):899-906. [PMID:6238017]

7. Axen K, Bishop M, Haas F. Respiratory load compensation in neuromuscular disorders. J Appl Physiol. 1988;64(6): 2659-66. [PMID:3403449]

8. Cader SA, Vale RG, Castro JC, Bacelar SC, Biehl C, Gomes MC, Cabrer WE, Dantas EH. Inspiratory muscle training improves maximal inspiratory pressure and may assist weaning in older intubated patients: A randomised trial. J Physiother. 2010;56(3):171-77. [PMID:20795923] http://dx.doi.org/10.1016/S1836-9553(10)70022-9

9. Martin AD, Smith BK, Davenport PD, Harman E, Gonzalez-Rothi RJ, Baz M, Layon AJ, Banner MJ, Caruso LJ, Deoghare H, Huang TT, Gabrielli A. Inspiratory muscle strength training improves weaning outcome in failure to wean patients: A randomized trial. Crit Care. 2011;15(2): R84. [PMID:21385346] http://dx.doi.org/10.1186/cc10081

10. Kellerman BA, Martin AD, Davenport PW. Inspiratory strengthening effect on resistive load detection and magnitude estimation. Med Sci Sports Exerc. 2000;32(11):1859-67. [PMID:11079514] http://dx.doi.org/10.1097/00005768-200011000-00007

11. Capdevila X, Lopez S, Bernard N, Rabischong E, Ramonatxo M, Martinazzo G, Prefaut C. Effects of controlled mechanical ventilation on respiratory muscle contractile properties in rabbits. Intensive Care Med. 2003;29(1):103-10. [PMID:12528030]

12. Ramirez-Sarmiento A, Orozco-Levi M, Guell R, Barreiro E, Hernandez N, Mota S, Sangenis M, Broquetas JM, Casan P, Gea J. Inspiratory muscle training in patients with chronic obstructive pulmonary disease: Structural adaptation and physiologic outcomes. Am J Respir Crit Care Med. 2002;166(11):1491-97. [PMID:12406842] http://dx.doi.org/10.1164/rccm.200202-075OC

13. De Troyer A. Differential control of the inspiratory intercostal muscles during airway occlusion in the dog. J Physiol. 1991;439:73-88. [PMID:1895248]

14. Pate KM, Davenport PW. Tracheal occlusions evoke respiratory load compensation and neural activation in anesthetized rats. J Appl Physiol. 2012;112(3):435-42.

[PMID:22074720]

http://dx.doi.org/10.1152/japplphysiol.01321.2010

15. Bernhardt V, Hotchkiss MT, Garcia-Reyero N, Escalon BL, Denslow N, Davenport PW. Tracheal occlusion conditioning in conscious rats modulates gene expression profile of medial thalamus. Front Physiol. 2011;2:24.

[PMID:21660287]

http://dx.doi.org/10.3389/fphys.2011.00024 
16. Smith BK, Martin AD, Vandenborne K, Darragh BD, Davenport PW. Chronic intrinsic transient tracheal occlusion elicits diaphragmatic muscle fiber remodeling in conscious rodents. PLoS ONE. 2012;7(11):e49264.

[PMID:23133678]

http://dx.doi.org/10.1371/journal.pone.0049264

17. Bernhardt V, Garcia-Reyero N, Vovk A, Denslow N, Davenport PW. Tracheal occlusion modulates the gene expression profile of the medial thalamus in anesthetized rats. J Appl Physiol. 2011;111(1):117-24. [PMID:21527662] http://dx.doi.org/10.1152/japplphysiol.01317.2010

18. Gasier HG, Riechman SE, Wiggs MP, Buentello A, Previs SF, Fluckey JD. Cumulative responses of muscle protein synthesis are augmented with chronic resistance exercise training. Acta Physiol (Oxf). 2011;201(3):381-89. [PMID:20804462] http://dx.doi.org/10.1111/j.1748-1716.2010.02183.x

19. Mauro A. Satellite cell of skeletal muscle fibers. J Biophys Biochem Cytol. 1961;9:493-95. [PMID:13768451] http://dx.doi.org/10.1083/jcb.9.2.493

20. Jayaraman A, Liu M, Ye F, Walter GA, Vandenborne K. Regenerative responses in slow-and fast-twitch muscles following moderate contusion spinal cord injury and locomotor training. Eur J Appl Physiol. 2013;113(1):191-200. [PMID:22644570]

21. Zammit PS, Partridge TA, Yablonka-Reuveni Z. The skeletal muscle satellite cell: The stem cell that came in from the cold. J Histochem Cytochem. 2006;54(11):1177-91. [PMID:16899758] http://dx.doi.org/10.1369/jhc.6R6995.2006

22. Schiaffino S, Reggiani C. Fiber types in mammalian skeletal muscles. Physiol Rev. 2011;91(4):1447-531. [PMID:22013216] http://dx.doi.org/10.1152/physrev.00031.2010

23. Leenaerts P, Decramer M. Respiratory changes in parasternal intercostal intramuscular pressure. J Appl Physiol. 1990;68(3):868-75. [PMID:2341353]

24. Pate KM, Davenport PW. Neural activation associated with chronic tracheal obstructions (TO) in conscious rats. FASEB J. 2010;24:1064-67.

25. Larsson L, Skogsberg C. Effects of the interval between removal and freezing of muscle biopsies on muscle fibre size. J Neurol Sci. 1988;85(1):27-38. [PMID:3385429] http://dx.doi.org/10.1016/0022-510X(88)90033-0

26. Levine S, Nguyen T, Taylor N, Friscia ME, Budak MT, Rothenberg P, Zhu J, Sachdeva R, Sonnad S, Kaiser LR, Rubinstein NA, Powers SK, Shrager JB. Rapid disuse atrophy of diaphragm fibers in mechanically ventilated humans. N Engl J Med. 2008;358(13):1327-35. [PMID:18367735] http://dx.doi.org/10.1056/NEJMoa070447
27. Roy RR, Pierotti DJ, Edgerton VR. Skeletal muscle fiber cross-sectional area: Effects of freezing procedures. Acta Anat (Basel). 1996;155(2):131-35. [PMID:8828711] http://dx.doi.org/10.1159/000147798

28. Reid WD, Huang J, Bryson S, Walker DC, Belcastro AN. Diaphragm injury and myofibrillar structure induced by resistive loading. J Appl Physiol. 1994;76(1):176-84. [PMID:8175503]

29. Scott A, Wang X, Road JD, Reid WD. Increased injury and intramuscular collagen of the diaphragm in COPD: Autopsy observations. Eur Respir J. 2006;27(1):51-59. [PMID:16387935] http://dx.doi.org/10.1183/09031936.06.00143004

30. Mantilla CB, Seven YB, Zhan WZ, Sieck GC. Diaphragm motor unit recruitment in rats. Respir Physiol Neurobiol. 2010;173(1):101-6. [PMID:20620243] http://dx.doi.org/10.1016/j.resp.2010.07.001

31. Huang $\mathrm{CH}$, Yang GG, Wu YT, Lee CW. Comparison of inspiratory muscle strength training effects between older subjects with and without chronic obstructive pulmonary disease. J Formos Med Assoc. 2011;110(8):518-26.

[PMID:21783021] http://dx.doi.org/10.1016/S0929-6646(11)60078-8

32. Martínez-Llorens J, Casadevall C, Lloreta J, Orozco-Levi M, Barreiro E, Broquetas J, Gea J. [Activation of satellite cells in the intercostal muscles of patients with chronic obstructive pulmonary disease]. Arch Bronconeumol. 2008;44(5):239-44. Spanish. [PMID:18448014] http://dx.doi.org/10.1016/S1579-2129(08)60038-5

33. Fry DK, Pfalzer LA, Chokshi AR, Wagner MT, Jackson ES. Randomized control trial of effects of a 10-week inspiratory muscle training program on measures of pulmonary function in persons with multiple sclerosis. J Neurol Phys Ther. 2007;31(4):162-72. [PMID:18172412] http://dx.doi.org/10.1097/NPT.0b013e31815ce136

34. Sheel AW, Reid WD, Townson AF, Ayas NT, Konnyu KJ; Spinal Cord Rehabilitation Evidence Research Team. Effects of exercise training and inspiratory muscle training in spinal cord injury: A systematic review. J Spinal Cord Med. 2008;31(5):500-508. [PMID:19086707]

35. Koopman R, Gleeson BG, Gijsen AP, Groen B, Senden JM, Rennie MJ, van Loon LJ. Post-exercise protein synthesis rates are only marginally higher in type I compared with type II muscle fibres following resistance-type exercise. Eur J Appl Physiol. 2011;111(8):1871-78.

[PMID:21234594] http://dx.doi.org/10.1007/s00421-010-1808-9

36. Tannerstedt J, Apró W, Blomstrand E. Maximal lengthening contractions induce different signaling responses in the type I and type II fibers of human skeletal muscle. J Appl Physiol. 2009;106(4):1412-18. [PMID:19112158] http://dx.doi.org/10.1152/japplphysiol.91243.2008 
37. Garma T, Kobayashi C, Haddad F, Adams GR, Bodell PW, Baldwin KM. Similar acute molecular responses to equivalent volumes of isometric, lengthening, or shortening mode resistance exercise. J Appl Physiol. 2007;102(1):135-43. [PMID:17008438] http://dx.doi.org/10.1152/japplphysiol.00776.2006

38. Prezant DJ, Aldrich TK, Richner B, Gentry EI, Valentine DE, Nagashima H, Cahill J. Effects of long-term continuous respiratory resistive loading on rat diaphragm function and structure. J Appl Physiol. 1993;74(3):1212-19. [PMID:8482660]

39. Rollier H, Bisschop A, Gayan-Ramirez G, Gosselink R, Decramer M. Low load inspiratory muscle training increases diaphragmatic fiber dimensions in rats. Am J Respir Crit Care Med. 1998;157(3 Pt 1):833-39. [PMID:9517599] http://dx.doi.org/10.1164/ajrccm.157.3.9512103

40. Truwit JD, Marini JJ. Validation of a technique to assess maximal inspiratory pressure in poorly cooperative patients. Chest. 1992;102(4):1216-19. [PMID:1395771] http://dx.doi.org/10.1378/chest.102.4.1216

41. Harikumar G, Moxham J, Greenough A, Rafferty GF. Measurement of maximal inspiratory pressure in ventilated children. Pediatr Pulmonol. 2008;43(11):1085-91.

[PMID:18846557] http://dx.doi.org/10.1002/ppul.20905

42. Verdijk LB, Gleeson BG, Jonkers RA, Meijer K, Savelberg $\mathrm{HH}$, Dendale P, van Loon LJ. Skeletal muscle hypertrophy following resistance training is accompanied by a fiber type-specific increase in satellite cell content in elderly men. J Gerontol A Biol Sci Med Sci. 2009;64(3):332-39. [PMID:19196907] http://dx.doi.org/10.1093/gerona/gln050

43. Petrella JK, Kim JS, Mayhew DL, Cross JM, Bamman MM. Potent myofiber hypertrophy during resistance training in humans is associated with satellite cell-mediated myonuclear addition: A cluster analysis. J Appl Physiol. 2008;104(6):1736-42. [PMID:18436694] http://dx.doi.org/10.1152/japplphysiol.01215.2007

44. Smith HK, Merry TL. Voluntary resistance wheel exercise during post-natal growth in rats enhances skeletal muscle satellite cell and myonuclear content at adulthood. Acta Physiol (Oxf). 2012;204(3):393-402. [PMID:21854550] http://dx.doi.org/10.1111/j.1748-1716.2011.02350.x

45. Kalhovde JM, Jerkovic R, Sefland I, Cordonnier C, Calabria E, Schiaffino S, Lømo T. "Fast" and "slow" muscle fibres in hindlimb muscles of adult rats regenerate from intrinsically different satellite cells. J Physiol. 2005;562(Pt 3):847-57. [PMID:15564285] http://dx.doi.org/10.1113/jphysiol.2004.073684

46. Zammit PS, Relaix F, Nagata Y, Ruiz AP, Collins CA, Partridge TA, Beauchamp JR. Pax 7 and myogenic progression in skeletal muscle satellite cells. J Cell Sci. 2006;119(Pt 9): 1824-32. [PMID:16608873] http://dx.doi.org/10.1242/jcs.02908

47. Gibson MC, Schultz E. The distribution of satellite cells and their relationship to specific fiber types in soleus and extensor digitorum longus muscles. Anat Rec. 1982;202(3):329-37.

[PMID:7072981]

http://dx.doi.org/10.1002/ar.1092020305

48. Relaix F, Montarras D, Zaffran S, Gayraud-Morel B, Rocancourt D, Tajbakhsh S, Mansouri A, Cumano A, Buckingham M. Pax3 and Pax7 have distinct and overlapping functions in adult muscle progenitor cells. J Cell Biol. 2006;172(1):91-102. [PMID:16380438] http://dx.doi.org/10.1083/jcb.200508044

49. Levine S, Nguyen T, Friscia M, Zhu J, Szeto W, Kucharczuk JC, Tikunov BA, Rubinstein NA, Kaiser LR, Shrager JB. Parasternal intercostal muscle remodeling in severe chronic obstructive pulmonary disease. J Appl Physiol. 2006;101(5):1297-1302. [PMID:16777998] http://dx.doi.org/10.1152/japplphysiol.01607.2005

50. Pette D, Sketelj J, Skorjanc D, Leisner E, Traub I, Bajrović F. Partial fast-to-slow conversion of regenerating rat fasttwitch muscle by chronic low-frequency stimulation. J Muscle Res Cell Motil. 2002;23(3):215-21. [PMID:12500901] http://dx.doi.org/10.1023/A:1020974710389

51. Decramer M, Jiang TX, Reid MB. Respiratory changes in diaphragmatic intramuscular pressure. J Appl Physiol. 1990;68(1):35-43. [PMID:2312477]

52. Altose MD, Stanley NN, Cherniack NS, Fishman AP. Effects of mechanical loading and hypercapnia on inspiratory muscle EMG. J Appl Physiol. 1975;38(3):467-73. [PMID:1150560]

53. Hershenson MB, Kikuchi Y, Tzelepis GE, McCool FD. Preferential fatigue of the rib cage muscles during inspiratory resistive loaded ventilation. J Appl Physiol. 1989;66(2): 750-54. [PMID:2708204]

54. Ross EZ, Nowicky AV, McConnell AK. Influence of acute inspiratory loading upon diaphragm motor-evoked potentials in healthy humans. J Appl Physiol. 2007;102(5):1883-90. [PMID: 17234806] http://dx.doi.org/10.1152/japplphysiol.00694.2006

55. Gea J, Hamid Q, Czaika G, Zhu E, Mohan-Ram V, Goldspink G, Grassino A. Expression of myosin heavy-chain isoforms in the respiratory muscles following inspiratory resistive breathing. Am J Respir Crit Care Med. 2000; 161(4 Pt 1):1274-78. [PMID:10764323] http://dx.doi.org/10.1164/ajrccm.161.4.99040103

56. Pizza FX, Peterson JM, Baas JH, Koh TJ. Neutrophils contribute to muscle injury and impair its resolution after lengthening contractions in mice. J Physiol. 2005;562(Pt 


\section{3):899-913. [PMID:15550464]}

http://dx.doi.org/10.1113/jphysiol.2004.073965

57. Esposito A, Germinario E, Zanin M, Palade PT, Betto R, Danieli-Betto D. Isoform switching in myofibrillar and excitation-contraction coupling proteins contributes to diminished contractile function in regenerating rat soleus muscle. J Appl Physiol. 2007;102(4):1640-48.

[PMID:17234797] http://dx.doi.org/10.1152/japplphysiol.01397.2006

58. Liu M, Stevens-Lapsley JE, Jayaraman A, Ye F, Conover C, Walter GA, Bose P, Thompson FJ, Borst SE, Vandenborne K. Impact of treadmill locomotor training on skeletal muscle IGF1 and myogenic regulatory factors in spinal cord injured rats. Eur J Appl Physiol. 2010;109(4):709-20. [PMID:20213470] http://dx.doi.org/10.1007/s00421-010-1392-z

59. McCarthy JJ, Mula J, Miyazaki M, Erfani R, Garrison K, Farooqui AB, Srikuea R, Lawson BA, Grimes B, Keller C, Van Zant G, Campbell KS, Esser KA, Dupont-Versteegden EE, Peterson CA. Effective fiber hypertrophy in satellite cell-depleted skeletal muscle. Development. 2011;138(17): 3657-66. [PMID:21828094] http://dx.doi.org/10.1242/dev.068858

60. Wang Q, McPherron AC. Myostatin inhibition induces muscle fibre hypertrophy prior to satellite cell activation. J Physiol. 2012;590(Pt 9):2151-65. [PMID:22393251]

61. Lee SJ, Huynh TV, Lee YS, Sebald SM, Wilcox-Adelman SA, Iwamori N, Lepper C, Matzuk MM, Fan CM. Role of satellite cells versus myofibers in muscle hypertrophy induced by inhibition of the myostatin/activin signaling pathway. Proc Natl Acad Sci USA. 2012;109(35):E2353-60. [PMID:22869749] http://dx.doi.org/10.1073/pnas.1206410109

62. Kadi F, Thornell LE. Training affects myosin heavy chain phenotype in the trapezius muscle of women. Histochem Cell Biol. 1999;112(1):73-78. [PMID:10461814] http://dx.doi.org/10.1007/s004180050393

63. Geiger PC, Cody MJ, Macken RL, Sieck GC. Maximum specific force depends on myosin heavy chain content in rat diaphragm muscle fibers. J Appl Physiol. 2000;89(2): 695-703. [PMID:10926656]

Submitted for publication December 21, 2012. Accepted in revised form December 30, 2013.

This article and any supplementary material should be cited as follows:

Smith BK, Mathur S, Ye F, Martin AD, Attia Truelson S, Vandenborne K, Davenport PW. Intrinsic transient tracheal occlusion training and myogenic remodeling of rodent parasternal intercostal fibers. J Rehabil Res Dev. 2014;51(5):841-54.

http://dx.doi.org/10.1682/JRRD.2012.12.0232

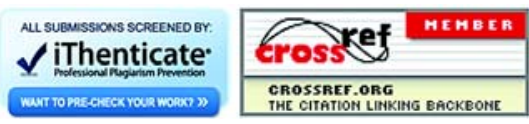

